\title{
Inghaft.
}

\section{Exite abteilung.}

Ungelegentheiten der Kommunal. und ftaatliḑen Derwaltungsbejirte.

I. Provimgialvertimule. Eette 11. Areije.

D. \$robinzialabgaben

A. 28 ablangelegenfeiten . . . . . . . . . . . . .

G. Prmenangelegentreiten . . . . . . . . . . . . . 3

1II. Stabte.

F. 3wangsetatifienung . . . . . . . . . . . . . . . 3

A. Bemeinbeabgaben . . . . . . . . . . . . . . . 4

c. Berbältnifife ber ỉäbiifden Sommunalbeamten . . . . . . 16

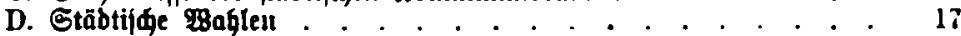

E. Pejondere Öngelegengeiten ber stabtgemeinden . . . . . . 20

F. Euffictabegburbe . . . . . . . . . . 21

IV. Amtsuetbinbe

v. Raubgemetuben nub Ointsibezirte.

A. Bemeindeabgaben und Dienite, Bemeinbevermügen . . . . . 23

C. Brenzen Der Bremeinde = und Ğut\$bejirte . . . . . . . 25

E. Bemeinbenaglen . . . . . . . . . 26

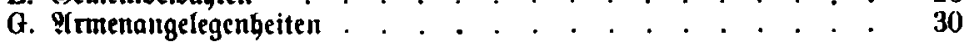

3weite Abteilung.

Kultus, Shule und perfonenftand.

VII. Die Rirde

IX. Die Shule.

B. Eqdulabgaben . . . . . . . . . . . . . 32

c. ङ中ulbauten . . . . . . 36

\section{Dritte abteilung.}

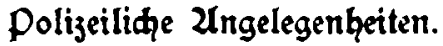

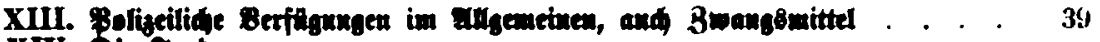

XIV. Die 3agb.

B. Jagbbezirte und Jagdvetpadturg . . . . . . . . . . . 43

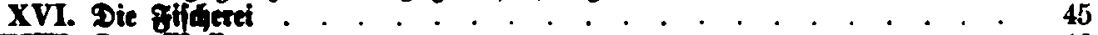

XVII. Das Gaffer . . . . . . . . . . . . . . . . . . . . 46

XIX. Die Bege . . . . . . . . . . . . . . . . . . . . . 49

XX. Die Gewerke.

H. æaanbergemerbejकeine . . . . . . . . . . . . . . . 63

J. Bewetbepoligei ? . . . . . . . . . 64

L. Jnnumgen . . . . . . . . . . . . . . . . . . . 84

0. Eewerbegeridt . . . . . . . . . . . . 65 


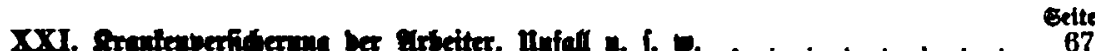

XXII ges Derodex

XXIII. Gníebelungen unb stolonien . . . . . . . . . . . . . . . 76

XXIV. Beríderungen . . . . . . . . . . . . . . . . . . . 77

Diexte ubteilung.

Der Derwaltungsprojef.

XXVIII Des Streituetfulfen . . . . . . . . . . . . . . . . . . 79

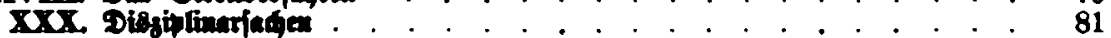

XXXI. smifilte . . . . . . . . . . . . . . . . . . . . . . 83

\section{fünfte Ubtetlung. \\ Entjheidungen in Staats.Steuerjahen.}

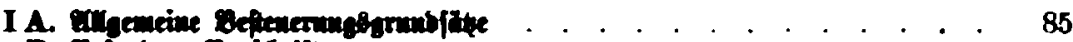

B. Defoubere Bordigritten

a) Eintommen aus Sapltalbermigen . . . . . . . . . . . 90

b) Qrumbermogen

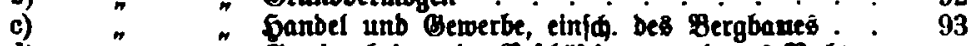

d) " " Bewinn Gringender Bejdaftigung unb auB Mediten auf periobifide Eebungen $x$. . . . . 94

e) ber altiengeferéfiaften $\mathfrak{u}$. ๆ. w. . . . . . . . 98

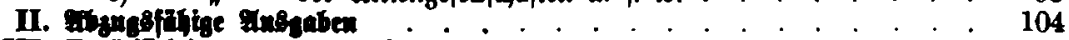

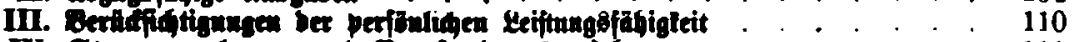

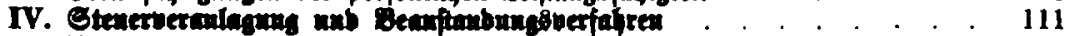

V. Alethtemittel . . . . . . . . . 115

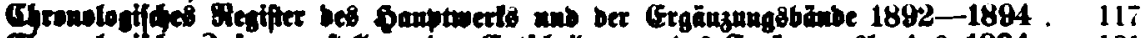

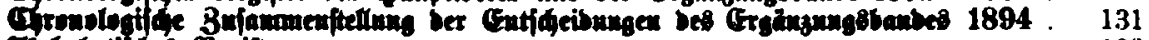

enpqubetif 